\title{
Translation and cultural adaptation of the Game Dice Task to Brazilian population
}

\author{
Tradução e adaptação transcultural do "Game Dice Task" para população brasileira \\ Patricia Rzezak, Hanna Karen Moreira Antunes, Sérgio Tufik, Marco Túlio de Mello
}

\begin{abstract}
Objective: The Game Dice Task (GDT) was developed to measure decision making under known risk. The aim of this study was to translate and adapt the GDT to a Brazilian population. Method: After the GDT was translated and back-translated to Brazilian Portuguese and evaluated by eight bilingual judges, 175 Brazilian adults were divided into two groups - 160 healthy volunteers and 15 traumatic brain injury (TBI) patients - and had completed the GDT. Results: Differences between genders, but not age, were observed in the healthy volunteer sample. Males more frequently chose a combination of three dice while females preferred four dice. TBI patients were more impulsive than healthy volunteers; they less frequently chose a combination of three dice and made more risky decisions. Conclusion: Because of the rigorous process used to translate and adapt the GDT and the differences observed between patients with TBI and healthy volunteers, the Brazilian GDT was considered satisfactory for research purposes.
\end{abstract}

Key words: cognition, psychometrics, decision making.

RESUMO

Objetivo: O Game Dice Task (GDT) foi desenvolvido para avaliar a tomada de decisão de indivíduos sob situações específicas de risco conhecido. 0 objetivo deste estudo foi traduzir e adaptar o GDT para a população brasileira. Métodos: Após ter sido traduzido e retrotraduzido para o português e ter sido avaliado por oito juízes bilíngues, 175 adultos brasileiros completaram o GDT - 160 adultos saudáveis e 15 pacientes com traumatismo cranioencefálico (TCE). Resultados: Foram observadas diferenças no desempenho quanto ao gênero, mas não quanto à idade, nos adultos saudáveis. Homens escolheram mais frequentemente a combinação com três dados, enquanto as mulheres preferiram quatro dados. Pacientes com TCE foram mais impulsivos, escolheram com menor frequência a combinação de três dados e tomaram decisões mais arriscadas. Conclusão: Por causa do rigoroso processo utilizado pra traduzir e adaptar o teste GTD e do poder de discriminação entre as amostras de adultos saudáveis e com TCE, a versão brasileira desse teste foi considerada satisfatória para utilização em pesquisa.

Palavras-Chave: cognição, psicometria, tomada de decisões.

The ability to decide between two or more options and behaviors in a specific situation is referred to as decision-making ability. Thus, decision making is an everyday life function, and disturbances of this ability can lead to severe problems in various aspects of life, such as social interactions ${ }^{1}$.

Different patient groups are reported to be deficient in decision making although the sensitivity and specificity of such deficits are not clear. Among such groups of patients, are those with orbitofrontal/ventromedial prefrontal cortex lesions ${ }^{2,3}$; patients with frontal lobe dysfunctions due to substance addiction ${ }^{4-6}$; and patients with Parkinson's and Huntington's disease $\mathrm{e}^{7,8}$, schizophrenia ${ }^{9}$, obsessive-compulsive disorder ${ }^{10}$ or anorexia nervosa ${ }^{11}$.
The types of decision making vary in terms of the degree of available information provided about outcomes and their probabilities. In some situations, the consequences of a decision and its probability are implicit (decision making under ambiguity), and the decision maker has to initially infer the quality of the options by processing feedback of previous decisions. In other situations (decision making under risk), the decider has the explicit rules and must choose by calculating the risk of disadvantageous options ${ }^{1}$.

One of the most frequently used cognitive tasks to evaluate decision making in ambiguous situations is the Iowa Gambling Task (IGT) ${ }^{2}$. In this test, the subject is required to choose between four different card stacks (A, B, C or D)

Department of Psychobiology, Universidade Federal de São Paulo (UNIFESP), São Paulo SP, Brazil.

Correspondence: Marco Túlio de Mello; Rua Professor Francisco de Castro 93, 04020-050 São Paulo SP - Brasil; E-mail: tmello@demello.net.br

Support: This work was supported by grants from Associação Fundo de Incentivo à Pesquisa (AFIP), Coordenação de Aperfeiçoamento de Pessoal de Nivel Superior (CAPES) and Fundação de Amparo à Pesquisa do Estado de São Paulo (CEPID n 98/14303-3 to ST). Marco Túlio de Mello and Sérgio Tufik are

recipients of the Conselho Nacional de Desenvolvimento Científico e Tecnológico (CNPq) fellowship.

Conflict of interest: There is no conflict of interest to declare.

Received 06 January 2012; Received in final form 30 July 2012; Accepted 06 August 2012 
during 100 trials. The choices are either advantageous or disadvantageous, but the consequences of each choice are unknown. The rules for gains and losses are not explained to the subjects. Two out of the four stacks will lead to an advantageous outcome because they result in moderate gains and moderate or low losses, leading to a positive final balance. The remaining two stacks are disadvantageous, because, even though the gains are higher than in the other two alternatives, the losses are very high, which results in a negative balance in the long term.

To measure decision under risk, Brand et al. ${ }^{12}$ developed a test called the Game Dice Task (GDT). In this test, subjects are asked to predict the outcome of a dice throw. A subject must decide between different alternatives (one single number or a combination of numbers) that are explicitly related to a specific amount of gain and loss and that have obvious winning probabilities (1:6 to 4:6). Since the rules for gains and losses are explicitly provided, subjects can calculate the risk associated with each alternative from the beginning of the task and may thus use strategies to maximize profit.

The Brazilian population already has a Brazilian Portuguese version of the $\mathrm{IGT}^{13}$. Nevertheless, we still do not have an adaptation of GDT. Accordingly, the aims of this study a were (i) to translate and adapt the GDT to Brazilian Portuguese and (ii) to evaluate the construct validity of the Brazilian Portuguese version of GDT.

\section{METHODS}

\section{Participants}

Before participating in this study, all subjects signed an informed consent form approved by the local Ethics Committee (CEP \#1858/09). All procedures were in accordance with the Declaration of Helsinki (1996). One hundred and eighty-three subjects participated in the study (94 men and 89 women). The subjects were divided into three groups: bilingual speakers, healthy subjects and subjects with traumatic brain injury (TBI) (Table 1).

- Bilingual speakers - this group comprised eight participants (two men and six women) with a mean age of $29.38 \pm 9.97$ years (age range from 20 to 50 years) and $15.88 \pm 2.00$ years of education. To be included in this group, volunteers had to be an English teacher $(n=4)$ or a translator and English reviewer $(n=4)$ with a proficiency certificate in English. Participants were recruited through advertisements in English-speaking schools.

- Healthy subjects - one hundred and sixty participants (77 men and 83 women) were included in this group. Volunteers had a mean age of $28.99 \pm 7.22$ years (age range from 19 to 52 years) and $16.35 \pm 3.18$ years of education. Volunteers who were using a psychotropic medication, who had a previous history of a neurological disorder or a mental illness, with a Self-Report Questionnaire (SRQ-20) ${ }^{14,15}$ score $>6$ for men and $>8$ for women were excluded of this group. Participants were mostly graduate and post-graduate students from Universidade Federal de São Paulo who were recruited through local advertisements.

- Traumatic Brain Injury patients - fifteen male patients with a diagnosis of a closed TBI composed this group. Patients had a mean age of 33.67 \pm 11.11 years (age range from 19 to 50 years) and $9.47 \pm 4.36$ years of education. To be included in this group, patients had to be referred by a neurologist and must have been diagnosed with a moderate or severe TBI (with a closed head injury) for at least six months. We did not include patients with signs of mental confusion or post-traumatic amnesia, those who could not clearly express ideas and those with comprehension deficits or who had history of drug or alcohol abuse. Patients were recruited from the Neurosurgery Ambulatory department of the Medical School Hospital at the Universidade Federal de São Paulo.

\section{Procedures}

\section{Translation of Game Dice Task}

The translation and adaptation of the GDT to a Brazilian population comprised four steps. First, the original English version of the GDT was translated to Portuguese by a Brazilian linguist (English teacher). Next, a native-English-speaking teacher with proficiency both in English and Portuguese made the back translation. Then, the back-translated version was compared with the original translation by two authors with English proficiency (P. R. and H. K. A.) who identified words that did not reflect the original meaning and that thus needed a semantic adaptation. The new Brazilian version was then sent to the original authors of the GDT, who, after approval, developed the Brazilian Game Dice Task software. Minor Portuguese spelling errors were corrected and, finally, the last version of the test was approved by all authors.

\section{Sample of bilingual speakers}

Eight bilingual speakers (four English teachers and four translators/English reviewers) were assessed with the English and Brazilian versions of GDT with a two-week interval between evaluations. To avoid the bias of presentation sequence, half of the sample started with the Brazilian version and the other half started with the English version. Volunteers were asked to make comments about how easy it was to understand each version and, after completing both versions, they indicated whether they felt that the versions were similar. All questions and remarks made during the test were recorded by the examiner.

\section{Sample of healthy subjects}

Healthy volunteers completed the Brazilian version of the GDT for two main purposes: to check for possible 
misunderstanding and to have preliminary normative data of the Brazilian population in the GDT. All of the questions and remarks made during test instructions were also recorded.

\section{Sample of patients with traumatic brain injury}

Fifteen patients with TBI answered the Brazilian version of the GDT to verify the discriminant validity of the Brazilian Game Dice Task.

\section{Data analysis}

Tables 1 and 2 provide descriptive data for the healthy volunteers' performances on the GDT. After verifying the normality of the data with the Kolmogorov-Smirnov test, differences in performance due to sex (male and female) and age (more or less than 27 years) were verified with the Student ttest. Then, Cronbach's alpha was calculated to determine the reliability of the data. In order to evaluate the discriminant validity, TBI patients' and healthy volunteers' performances (males) were compared with the Student $t$-test.

\section{RESULTS}

Male and female healthy volunteers differed only in the number of choices of three and four combinations of dice. While males more frequently chose the combination of three dice $(t=2.93 ; p=0.004)$, females more frequently chose the combination of four dice ( $t=-2.27 ; \mathrm{p}=0.025)$ (Table 3$)$. No differences were found between age groups in GDT subscales (Table 4).

Cronbach's alpha coefficient was 0.918 , considering the 18 possibilities of dice choices.

To control for gender differences, only male healthy volunteers $(n=77)$ were compared with TBI patients. Patients with TBI less frequently chose the combination of three dice $(t=4.03 ; p=0.001)$, made more risky choices $(t=-3.27 ; p=0.002)$ and made fewer nonrisky choices $(\mathrm{t}=3.27 ; \mathrm{p}=0.002)$. Moreover, patients with TBI had an inferior net-score $(t=3.27 ; \mathrm{p}=0.002)$ (Table 5).

\section{DISCUSSION}

The present study presents a Brazilian adaptation of the GDT, a test originally developed by Brand et al. ${ }^{12}$ to evaluate decision making under risk. To the best of our knowledge, previously, there has not been a specific test to measure this cognitive ability available in Brazilian Portuguese. The relevance of pursuing an equivalent adaptation of the original test, designed in a foreign cultural background, has been emphasized and is recommended by local committees that manage psychological evaluation ${ }^{16}$.

Several steps were followed to guarantee the proper translation and semantic adaptation of GDT from the original English version to the Brazilian Portuguese version. First,

Table 1. Descriptive data of the healthy volunteer sample.

\begin{tabular}{|c|c|c|c|c|c|c|c|}
\hline \multirow{2}{*}{$\begin{array}{l}\text { Healthy volunteers } \\
(n=160)\end{array}$} & \multirow{2}{*}{ Mean (SD) } & \multirow{2}{*}{ Median } & \multirow{2}{*}{ Minimum } & \multirow{2}{*}{ Maximum } & \multirow{2}{*}{ Range } & \multicolumn{2}{|c|}{$95 \%$ Confidence Interval } \\
\hline & & & & & & Lower bound & Upper bound \\
\hline Age & $28.99(7.22)$ & 27.00 & 19 & 52 & 33 & 27.87 & 30.12 \\
\hline Education & 16.35 (3.18) & 16.00 & 4 & 28 & 24 & 15.85 & 16.85 \\
\hline N1_GDT & 2.18 (3.37) & 1.00 & 0 & 18 & 18 & 1.66 & 2.71 \\
\hline N2_GDT & $3.65(3.31)$ & 3.00 & 0 & 17 & 17 & 3.13 & 4.17 \\
\hline N3_GDT & $5.52(3.60)$ & 5.00 & 0 & 17 & 17 & 4.96 & 6.08 \\
\hline N4_GDT & $6.64(0.40)$ & 6.00 & 0 & 18 & 18 & 5.86 & 7.42 \\
\hline Risky_GDT & $5.83(0.40)$ & 4.00 & 0 & 18 & 18 & 5.04 & 6.62 \\
\hline Nonrisky GDT & $12.16(0.40)$ & 14.00 & 0 & 18 & 18 & 11.37 & 12.95 \\
\hline Net-score GDT & 6.33 (10.09) & 10.00 & -18 & 18 & 36 & 4.76 & 7.91 \\
\hline
\end{tabular}

N (1-4): number of choices; SD: Standard Deviation; GDT: Game Dice Task.

Table 2. Scores for the Game Dice Task converted into a percentile for the healthy volunteer sample.

\begin{tabular}{|c|c|c|c|c|c|c|c|}
\hline $\begin{array}{l}\text { Healthy volunteers } \\
(n=160)\end{array}$ & $\mathrm{P} 5$ & P10 & P25 & P50 & P75 & P90 & P95 \\
\hline N1_GDT & 0.00 & 0.00 & 0.00 & 1.00 & 3.00 & 6.90 & 10.95 \\
\hline N2_GDT & 0.00 & 0.10 & 1.00 & 3.00 & 5.00 & 8.00 & 10.00 \\
\hline N3_GDT & 0.00 & 1.00 & 3.00 & 5.00 & 7.75 & 10.00 & 12.95 \\
\hline N4_GDT & 0.00 & 0.00 & 2.00 & 6.00 & 10.00 & 13.00 & 15.00 \\
\hline Risky_GDT & 0.00 & 1.00 & 2.00 & 4.00 & 9.75 & 13.00 & 17.00 \\
\hline Nonrisky GDT & 1.00 & 5.00 & 8.00 & 14.00 & 16.00 & 17.00 & 18.00 \\
\hline Net-score GDT & -16.00 & -8.00 & -1.75 & 10.00 & 14.00 & 16.00 & 18.00 \\
\hline
\end{tabular}

N (1-4): number of choices; P: percentile; GDT: Game Dice Task. 
Table 3. Comparison of the performance of male and female healthy volunteers.

\begin{tabular}{lcccc} 
& Male & Female & & \\
\cline { 1 - 3 } $\begin{array}{l}\text { Healthy } \\
\text { volunteers }\end{array}$ & Mean (SD) & Mean (SD) & t & p-value \\
\cline { 1 - 3 } N1_GDT & $1.97(3.00)$ & $2.37(3.68)$ & -0.75 & 0.455 \\
N2_GDT & $3.94(3.49)$ & $3.39(3.12)$ & 1.05 & 0.295 \\
N3_GDT & $6.36(3.87)$ & $4.73(3.15)$ & 2.93 & $0.004^{\star}$ \\
N4_GDT & $5.73(4.76)$ & $7.49(5.08)$ & -2.27 & $0.025^{\star}$ \\
Risky_GDT & $5.91(5.01)$ & $5.76(5.11)$ & 0.19 & 0.852 \\
Nonrisky GDT & $12.09(5.01)$ & $12.23(5.12)$ & -0.17 & 0.863 \\
Net-score GDT & $1.73(0.45)$ & $1.77(0.42)$ & -0.18 & 0.857 \\
\hline
\end{tabular}

N (1-4): number of choices; SD: Standard Deviation; GDT: Game Dice Task; t: Student $t$-test value; ${ }^{\star}$ significant.

Table 4. Comparison of the performance of healthy volunteers in two age groups.

\begin{tabular}{|c|c|c|c|c|}
\hline & $\begin{array}{c}<27 \text { years } \\
\text { old }\end{array}$ & $\begin{array}{c}>27 \text { years } \\
\text { old }\end{array}$ & \multirow[t]{2}{*}{$t$} & \multirow[t]{2}{*}{ p-value } \\
\hline Healthy volunteers & Mean (SD) & Mean (SD) & & \\
\hline N1_GDT & $1.93(3.03)$ & $2.67(3.93)$ & -1.30 & 0.194 \\
\hline N2_GDT & $3.35(2.85)$ & $4.24(4.03)$ & -1.45 & 0.150 \\
\hline N3_GDT & $5.87(3.62)$ & $4.83(3.49)$ & 1.73 & 0.085 \\
\hline N4_GDT & $6.84(4.85)$ & $6.26(5.28)$ & 0.69 & 0.489 \\
\hline Risky_GDT & $5.28(4.52)$ & $6.91(5.84)$ & -1.79 & 0.077 \\
\hline Nonrisky GDT & $12.71(4.53)$ & $11.09(5.84)$ & 1.78 & 0.079 \\
\hline Net-score GDT & $7.42(9.04)$ & $4.19(11.68)$ & 1.78 & 0.078 \\
\hline
\end{tabular}

N (1-4): number of choices; SD: Standard Deviation; GDT: Game Dice Task; t: Student $t$-test value.

Table 5. Comparison between patients with Traumatic Brain Injury and healthy volunteers for the Game Dice Task.

\begin{tabular}{lcccc} 
& $\begin{array}{c}\text { Healthy } \\
\text { volunteers } \\
(\mathrm{n}=77)\end{array}$ & $\begin{array}{c}\text { TBI } \\
\text { patients } \\
(\mathrm{n}=15)\end{array}$ & $\mathrm{t}$ & $\mathrm{p}$-value \\
\cline { 1 - 4 } Healthy volunteers & Mean (SD) & Mean (SD) & & \\
\cline { 1 - 4 } N1_GDT & $1.97(3.00)$ & $3.87(5.85)$ & -1.22 & 0.240 \\
N2_GDT & $3.94(4.49)$ & $7.00(6.93)$ & -1.67 & 0.115 \\
N3_GDT & $6.36(3.87)$ & $2.13(2.80)$ & 4.03 & $0.001 *$ \\
N4_GDT & $5.73(4.76)$ & $5.00(7.11)$ & 0.50 & 0.621 \\
Risky_GDT & $5.91(5.01)$ & $10.87(7.03)$ & -3.27 & $0.002^{*}$ \\
Nonrisky GDT & $12.09(5.01)$ & $7.13(1.82)$ & 3.27 & $0.002^{*}$ \\
Net-score GDT & $6.18(10.01)$ & $-3.73(3.63)$ & 3.27 & $0.002 *$ \\
\hline
\end{tabular}

N (1-4): number of choices; SD: Standard Deviation; GDT: Game Dice Task; TBI: Traumatic Brain Injury; t: Student $t$-test value; *significant.

translation and back-translation was undertaken by translators who were familiar with the source and target languages and who were competent in the material covered by the source test. Then, a sample of bilingual judges checked for errors, compared the source and translated versions of the test and decided whether differences between translations could result in nonequivalence of meaning in the two populations of interest ${ }^{17}$. Only after this procedure, a sample of healthy volunteers completed the Brazilian GDT, and potential misunderstandings in the instructions were ruled out. A high internal consistency was observed in the healthy volunteers' GDT performance; Cronbach's alpha was $0.918^{18}$. For that reason, we considered our translation and adaptation of GDT to Brazilian population to be satisfactory.

Interestingly, we found a different pattern of choices between males and females in our sample of healthy volunteers. While males more frequently chose a combination of three dice, females preferred the combination of four dice. Because both types of choices are considered nonrisky decisions, it would be incorrect to state that a specific gender outperformed the other; nevertheless, it was evident that males and females tended to use different strategies while deciding between situations with explicit rules for gains and losses.

To the best of our knowledge, this is the first study to investigate differences in gender performance in a healthy sample using the GDT. However, there are a few studies with the IGT showing that men have a better performance than women ${ }^{19,20}$. One explanation for our apparently contradictory findings is that these two tests measure different types of decision making ${ }^{21}$. In particular, males may perform better in situations that require the individuals to keep track and remember the gains and losses from previous trials and thus outperform women in IGT, but not in GDT. Moreover, this ability may depend on working memory, which is involved in short-term memory and updating stored information ${ }^{22}$. In favor of this notion, it is well known that males have better visual working memory than females ${ }^{23}$.

In addition to that, the lack of differences regarding age in decision making is consistent with previous studies ${ }^{24,25}$. There is evidence that decision making develops throughout childhood reaches its full potential in young adulthood and begins to decline in older adulthood ${ }^{26,27}$. Our sample was composed of people from 19 to 52 years old and, thus, age differences were not expected in the sample. Because of the size of our sample, we were not able to divide volunteers into smaller age groups; in this way, these data should be interpreted with caution.

To measure discriminant validity of the GDT, a sample of patients with moderate to severe TBI were evaluated. It is well documented that patients with acquired brain injury and with TBI consistently show deficits in several aspects of executive functioning and decision making ${ }^{28,29}$. Sigurdardotti et al..$^{29}$ demonstrated that $83 \%$ of people with intracranial lesions and $71 \%$ of those without lesions, who were not in acute phase of recovery, were deficient in a decision-making task. In our study, patients with TBI were more impulsive than the healthy sample, chose fewer combinations of three dice and made more risky decisions overall.

Some measures were taken in order to minimize confounding variables. First, considering the previously discussed gender differences, only male healthy subjects were included in this analysis. Second, only patients with moderate and severe TBI, who had a lesion for at least six months, were recruited as patients, since those with mild TBI may not 
experience cognitive impairments after the brain lesion ${ }^{30}$. The finding of TBI patients being more impulsive than healthy volunteers suggests that the GDT was able to discriminate patients from healthy volunteers and demonstrated that the GDT is an interesting tool to investigate decision making both in a healthy and neurologically impaired sample.

Some may point out that we had a small sample of healthy volunteers. Nevertheless, the purpose of this study was not to provide normative data for a validation study of GDT, bu to present preliminary data that could be used to support the translation and adaptation of the task to Brazilian population. However, we recruited a homogeneous sample with similar backgrounds, who were mostly post-graduate students with no history of neurological or psychiatric disorders. It would be interesting to replicate these findings with a broader sample including a broader age range.

In conclusion, we presented a new methodology to evaluate decision making under explicit rules for gains and losses that was translated and adapted for a Brazilian population and that could be considered valid. Therefore, the Brazilian GDT may now be used for research purposes. Yet, future studies must evaluate different clinical populations and expand the age range of the sample population in order to validate this test for Brazil.

\section{References}

1. Labudda K, Frigge K, Horstmann S, et al. Decision making in patients with temporal lobe epilepsy. Neuropsychologia 2009;47:50-58.

2. Bechara A, Tranel D, Damasio H. Characterization of decision-making deficit of patients with ventromedial prefrontal cortex lesions. Brain 2000;123:2189-2202.

3. Manes F, Sahakian B, Clark L, et al. Decision-making processes following damage to the prefrontal cortex. Brain; 2002;125:624-639.

4. Fellows LK, Farah MJ. Different underlying impairments in decisionmaking following ventromedial and dorsolateral frontal lobe damage in humans. Cereb Cortex 2005;15:58-63.

5. Bechara A, Damasio H. Decision-making and addiction (Part I): impaired activation of somatic states in substance dependent individuals when pondering decisions with negative future consequences. Neuropsychologia 2002;40:1675-1689.

6. Bechara A, Dolan S, Hindes A. Decision-making and addiction (Part II): myopia for the future or hypersensitivity to reward? Neuropsychologia 2002;40:1690-1705

7. Stout JC, Rodawalt WC, Siemers ER. Risky decision making in Huntington's disease. J Int Neuropsychol Soc 2001;7:92-101.

8. Thiel A, Hilker R, Kessler J, Habedank B, Herholz K, Heiss WD. Activation of basal ganglia loops in idiopathic Parkinson's disease: a PET study. J Neural Transm 2003;110:1289-1301.

9. Whitney KA, Fastenau PS, Evans JD, Lysaker PH. Comparative neuropsychological function in obsessive-compulsive disorder and schizophrenia with and without obsessive-compulsive symptoms. Schizophr Res 2004;69:75-83.

10. Cavedini P, Riboldi G, D’Annucci A, Belotti P, Cisima M, Bellodi L. Decision-making heterogenity in obsessive compulsive disorder: ventromedial prefrontal cortex function predicts different treatment outcomes. Neuropsychologia 2002;40:205-211.

11. Cavedini P, Bassi T, Ubbiali A, et al. Neuropsychological investigation of decision-making in anorexia nervosa. Psychiatry Res 2004;127:259-266.

12. Brand M, Fujiwara E, Borsutzky S, Kalbe E, Kessler J, Markowitsch HJ. Decision-making deficits of Korsakoff patients in a new gambling task with explicit rules: Associations with executive functions. Neuropsychology 2005;19:267-277.

13. Malloy-Diniz LF, Leite WB, Moraes PHP, Correa H, Bechara A, Fuentes F. Brazilian Portuguese version of the lowa Gambling Task: transcultural adaptation and discriminant validity. Rev Bras Psiquiatr 2008;30: $144-148$

14. Harding TW, Arango MV, Baltazar J, et al. Mental disorders in primary health care; a study of their frequency and diagnosis in four developing countries. Psychol Med 1980;10:231-241.

15. Mari JJ, Williams P. A validity study of a Psychiatry Screening Questionnaire (SRQ-20) in primary care in the city of São Paulo. Brit J Psychiatr 1986;148:23-26.
16. Conselho Federal de Psicologia. Resolução CFP 002/2003 [Internet] [cited 2011 Oct 5]. Available from: http://200.199.243.195/legislacao/ doc/resolucao2003_002.doc

17. International Test Commission. ITC guidelines on adapting tests [Internet]. International Test Commission. 2000 [cited 2012 Sep 10]. Available from: http://www.intestcom.org

18. Cummings SR, Stewart AL, Hulley SB. Designing questionnaires and data collection instruments. In: Hulley SB, Cummings SR, Browner WS, Grady D, Hearst N, Newman TB (Eds). Designing clinical research. 2nd ed. Philadelphia: Lippincott Williams \& Wilkins 2001: 231-245.

19. Bolla KI, Eldreth DA, Matochik JA, Cadet JL. Sex-related differences in a gambling task and its neurological correlates. Cereb Cortex 2004;14:1226-1232.

20. Overman WH. Sex differences in early childhood, adolescence, and adulthood on cognitive tasks that rely on orbital prefrontal cortex. Brain Cogn 2004;55:134-147.

21. Brand M, Labudda K, Markowitsch HJ. Neuropsychological correlates of decision-making in ambiguous and risky situations. Neural Netw 2006;19:1266-1276.

22. Baddeley A. Working memory. Science 1992;255:556-559.

23. Lejbak L, Crossley M, Vrbancic M. A male advantage for spatial and object but not verbal working memory using the n-back task. Brain Cogn 2011;76:191-196.

24. Dror IE, Katona M, Mungur K. Age differences in decision making: to take a risk or not? Gerontology 1998;44:67-71.

25. MacPherson SE, Phillips LH, Della Sala S. Age, executive function, and social decision making: a dorsolateral prefrontal theory of cognitive aging. Psychol Aging 2002;17:598-609.

26. Mata R, von Helversen B, Rieskamp J. When easy comes hard: the development of adaptive strategy selection. Child Dev 2011;82: 687-700.

27. Worthy DA, Gorlick MA, Pacheco JL, Schnyer DM, Maddox WT. With age comes wisdom: decision making in younger and older adults. Psychol Sci 2011;22:1375-1380.

28. Hart T, Whyte J, Kim J, Vaccaro M. Executive function and selfawareness of "real-world" behavior and attention deficits following traumatic brain injury. J Head Trauma Rehabil 2005;20:333-347.

29. Sigurdardottir S, Jerstad T, Andelic N, Roe C, Schanke AK. Olfactory dysfunction, gambling task performance and intracranial lesions after traumatic brain injury. Neuropsychology 2010;24: 504-513.

30. West LK, Curtis KL, Greve KW, Bianchini KJ. Memory in traumatic brain injury: the effects of injury severity and effort on the Wechsler Memory Scale-III. J Neuropsychol 2011;5:114-125. 